\title{
ASPECTOS GERAIS DA HISTOPLASMOSE EM PEQUENOS ANIMAIS E IMPORTÂNCIA CLÍNICA
}

\author{
Ítala Rossana Costa Agostinho ${ }^{1}$ \\ Marina Alicea Santana Campos \\ Igor Carvalho dos Santos \\ Janyfer Amorim da Silva \\ Keith Marrone da Silva Barbosa
}

\begin{abstract}
RESUMO
Histoplasma capsulatum é o agente causador da histoplasmose, uma das principais doenças que acomete o sistema respiratório inferior de cães e gatos. Este patógeno é frequentemente isolado de fezes de aves e morcegos. A infecção ocorre por inalação dos esporos fúngicos em solos contaminados com as fezes. As manifestações clínicas da doença são divididas em infecção pulmonar, gastrointestinal, subclínica e disseminada. Esta revisão descreve como a doença ocorre em cães e felinos domésticos, seus achados clínicos, diagnóstico, tratamento e prevenção, evidenciando sua importância na clínica médica de pequenos animais.
\end{abstract}

Palavras-chave: fungos, histoplasmose, animais domésticos.

\section{GENERAL ASPECTS OF HISTOPLASMOSIS IN SMALL ANIMALS AND THE CLINICAL IMPORTANCE}

\begin{abstract}
Histoplasma capsulatum is the causative agent of histoplasmosis, one of the main diseases that affects the lower respiratory system of dogs and cats. This pathogen is often isolated from bird and bat droppings. Infection occurs by inhaling fungal spores in soil contaminated with faeces. The clinical manifestations of the disease are divided into pulmonary, gastrointestinal, subclinical and disseminated infection. This review describes how the disease occurs in dogs and domestic cats, their clinical findings, diagnosis, treatment and prevention, highlighting its importance in the medical clinic of small animals.
\end{abstract}

Key words: fungi, histoplasmosis, domestic animals

\section{ASPECTOS GENERALES DE LA HISTOPLASMOSIS EN PEQUEÑOS ANIMALES E IMPORTANCIA CLÍNICA}

\section{RESUMEN}

Histoplasma capsulatum es el agente causante de la histoplasmosis, una de las principales enfermedades que afecta al sistema respiratorio inferior de perros y gatos. Este patógeno a menudo se aísla de los excrementos de pájaros y murciélagos. La infección se produce al inhalar esporas de hongos en suelo contaminado con heces. Las manifestaciones clínicas de la enfermedad se dividen en infección pulmonar, gastrointestinal, subclínica y diseminada. . Esta revisión describe cómo se presenta la enfermedad en perros y gatos domésticos, sus hallazgos

\footnotetext{
${ }^{1}$ Universidade Federal do Piauí correspondência italarossana@gmail.com
} 
clínicos, diagnóstico, tratamiento y prevención, destacando su importancia en la clínica médica de pequeños animales.

Palabras-clave: hongos, histoplasmosis, animales domésticos

\section{INTRODUÇÃO}

A histoplasmose é uma enfermidade infecciosa sistêmica, oportunista, de caráter clínico agudo ou crônico, causada por fungos dimórficos do gênero Histoplasma, que acomete animais domésticos e os seres humanos (1).

Este patógeno é encontrado principalmente em solos úmidos e ricos em compostos nitrogenados, derivados de matéria orgânica em decomposição, principalmente excretas de morcegos e aves (2). O fungo tem uma maior prevalência em regiões de clima tropical e temperado, sua viabilidade podem perdurar durante anos, desde que em regiões de solo com pH ácido, temperaturas mais baixas e elevada umidade relativa do ar (3).

A forma de transmissão da histoplasmose em animais ocorre a partir da inalação dos esporos produzidos por micélios contidos nas fezes dos animais reservatórios (4). A doença não apresenta predileção racial, sexual ou de faixa etária, no entanto é considerada a segunda micose sistêmica mais diagnosticada em gatos $(4,5)$.

Diante da escassez de informações sobre esta micose no âmbito da veterinária, em especial na área de clínica de pequenos animais, o objetivo do presente trabalho foi caracterizar a histoplasmose nos cães e gatos em diferentes aspectos e ressaltar a importância desta afecção para a saúde animal.

\section{DESENVOLVIMENTO}

\section{Etiologia}

A histoplasmose é causada pelo fungo dimórfico Histoplasma capsulatum, de maneira taxonômica este patógeno é classificado como pertencente ao Reino Fungi, Classe Eurotiomyces, Ordem Onygenales, Família Ajellomycetaceae e Gênero Histoplasma (6).

São conhecidas três subespécies do $H$. capsulatum: $H$. capsulatum var. capsulatum, $H$. capsulatum var. duboisii e $H$. capsulatum var. farciminosum $(6,7)$.

Este fungo apresenta-se sob duas formas: miceliana e leviduriforme. No ambiente, manifesta-se na forma miceliana, com temperatura ótima de crescimento a $25^{\circ} \mathrm{C}$, é composto de hifas hialinas, septadas e ramificadas, que produzem microconídios e macroconídeos, estruturas esféricas, que medem em torno de $2-4 \mu \mathrm{m}$ e $5-18 \mu \mathrm{m}$, respectivamente. Na forma parasitária, o fungo é apresentado sob a forma leveduriforme, sendo encontrado no citoplasma de fagócitos mononucleares dos hospedeiros vertebrados (8).

Por ser caracterizado como fungo saprófita, seu principal habitat são solos ricos em matéria orgânica, contaminados com excrementos de diferentes espécies de morcegos e aves. As fezes destes animais são fontes de compostos nitrogenados, ideais para o desenvolvimento deste fungo (9). Além disso, o $H$. capsulatum pode ser encontrado em ocos de árvores, cavernas e construções abandonadas (10).

\section{Fisiopatologia}

Os animais domésticos adquirem a infecção através da inalação dos microconídeos fúngicos em sua fase miceliana, presentes no solo contaminado. Após o processo de inalação, os microconídeos adentram ao organismo animal e chegam aos alvéolos pulmonares. Devido

Agostinho IRC, Campos MAS, Santos IC, Silva JA, Barbosa KMS. Aspectos gerais da Histoplasmose em pequenos animais e importância clínica. Vet. e Zootec. 2021; v28: 001-005. 
à temperatura corporal do hospedeiro $\left(37^{\circ} \mathrm{C}\right)$, ocorre a conversão da forma miceliana do fungo para leveduriforme. No parênquima pulmonar, ocorre uma estimulação da resposta inflamatória do hospedeiro, levando ao quadro de infecção pulmonar primária (11).

$\mathrm{O} H$. capsulatum possui ainda a capacidade de multiplicar-se no interior das células do sistema reticulo endotelial, e através destas atingir os linfonodos pulmonares, ganhando acesso à circulação sanguínea e disseminando-se para vários órgãos, originando focos inflamatórios locais (12).

\section{Manifestações Clínicas}

As formas mais reconhecidas da histoplasmose são: infecção pulmonar, infecção disseminada e subclínica. Os sinais clínicos observados em cães com histoplasmose pulmonar correspondem à inapetência, anorexia, febre, aumento de volume dos linfonodos cervicais e axilares, dispneia, tosse e estertores pulmonares (13).

Os achados clínicos comuns de histoplasmose disseminada são inespecíficos e incluem perda de peso, letargia, inapetência e febre. Outros sinais observados são anemia (caracterizada como normocítica, normocrômica, não regenerativa), linfadenopatia, esplenomegalia e hepatomegalia ocasionalmente acompanhada por icterícia. A forma disseminada da doença pode envolver múltiplos órgãos, afetando principalmente fígado, baço e medula óssea $(3,14)$.

Além destas formas de manifestação, sinais de comprometimento gastrointestinal também são comuns, principalmente em cães infectados, podendo atingir o intestino grosso, causando uma diarreia com presença de sangue, muco e tenesmo, podendo evoluir ainda para diarreia aquosa. Embora incomum, podem ainda ocorrer sinais neurológicos, doenças dermatológicas, envolvimento ocular e ósseo (15).

\section{Diagnóstico}

O diagnóstico definitivo da histoplasmose baseia-se na associação dos sinais clínicos, anamnese, exames complementares e identificação do $H$. capsulatum no organismo do animal por exames laboratoriais (16).

O exame micológico é considerado o padrão-ouro do diagnóstico de histoplasmose, e fundamenta-se na observação das estruturas fúngicas do $H$. capsulatum por meio de exames diretos (citologia, histopatologia ou biópsia) e cultura de materiais biológicos, como por exemplo: líquor, lavado broncoalveolar ou medula óssea (17), além da possibilidade da realização de técnicas biomoleculares para a caracterização do agente.

\section{Tratamento e Prognóstico}

O tratamento para histoplasmose consiste na utilização de antifúngicos sistêmicos. O medicamento de primeira escolha para cães e gatos é o itraconazol, recomenda-se a posologia de uma ou duas vezes ao dia, na dose $10 \mathrm{mg} / \mathrm{kg}$, por via oral, durante um período de 4 a 6 meses, até pelo menos 2 meses após o desaparecimento das manifestações clínicas (3).

Os antifúngicos cetoconazol e a anfotericina B também são indicações úteis, no entanto, atualmente estes fármacos apresentam o uso limitado, levando em consideração o seu maior potencial de toxicidade no organismo (18).

O prognóstico da histoplasmose depende do estado imune do hospedeiro, virulência do fungo, grau do envolvimento sistêmico e da gravidade dos sinais clínicos associados. Em cães com histoplasmose pulmonar e em gatos que não estejam severamente debilitados, o prognóstico é considerado favorável, após um tratamento prolongado com itraconazol (1). 


\section{Medidas Preventivas}

A prevenção consiste em evitar a exposição dos animais aos solos potencialmente contaminados com fezes de aves e morcegos. Em áreas contaminadas, pode-se realizar a aplicação de produtos químicos, como a formalina na concentração de $3 \%$ no ambiente (8). Medidas para evitar a aerossolização dos esporos fúngicos incluem umedecer excretas de aves e morcegos e fazer uso de equipamentos de proteção individual, como a utilização de máscaras específicas, capazes de reter a forma infectante do fungo, para a realização da higienização do solo e demais locais contaminados (19).

\section{CONSIDERAÇÕES FINAIS}

A histoplasmose não é a enfermidade fúngica de maior ocorrência em animais e nos seres humanos, entretanto o conhecimento acerca de seus aspectos epidemiológicos, relacionados principalmente à transmissão, se faz importante na prevenção de infecções. Além disso, a associação desses aspectos com os sinais clínicos permite um diagnóstico precoce da doença com o intuito de impedir o desenvolvimento de quadros graves, que podem levar os pacientes a óbito.

\section{REFERÊNCIAS}

1. Almeida MA, Almeida-Silva F, Guimarães AJ, Almeida-Paes R, Zancopé-Oliveira RM. The occurrence of histoplasmosis in Brazil: a systematic review. Int $\mathrm{J}$ Infect Dis. 2019;86:147-56.

2. Larsuprom L, Duangkaew L, Kasorndorkbua C, Chen C, Chindamporn A, Worasilchai N. Feline cutaneous histoplasmosis: the first case report from Thailand. Med Mycol Case Rep. 2017;18:28-30.

3. Brömel C, Sykes J. Histoplasmosis in dogs and cats. Clin Tech Small Anim Pract. 2005;20(4):227-32.

4. Teles AJ, Gomes AR, Cabana AL, Osório LG, Martins AO, Waller SB, et al. Histoplasmose em cães e gatos no Brasil. Sci Anim Health. 2014;2(1):50-66.

5. Reinhart JM, KuKanich KS, Jackson T, Harkin KR. Feline histoplasmosis: fluconazole therapy and identification of potential sources of Histoplasma species exposure. J Feline Med Surg. 2012;14(12):841-8.

6. Kasuga T, et al. Filogeografia do patógeno fúngico Histoplasma capsulatum. Ecol Mol. 2003;12(12):3383-401.

7. Guillot J, Guérin C, Chermette R. Histoplasmosis in animals. In: Seyedmousavi S, Hoog GS, Guillot J, Verweij PE. Emerging and epidemic fungal infections in animals. New York: Springer; 2018. p.115-28. 
8. Nelson RW, Couto CG. Medicina interna de pequenos animais. 5a ed. Rio de Janeiro: Guanabara Koogan; 2015.

9. Ferreira R, Machado MLS, Spanamberg A, Bianchi SP, Aguiar J, Hummel J, et al. Infecções fúngicas do trato respiratório de cães e gatos. Acta Sci Vet. 2007;35 Supl 2:s2858.

10. Ferreira MS, Borges AS. Histoplasmosis. Rev Soc Bras Med Trop. 2009;42(2):192-8.

11. Teixeira MM, Patané JSL, Taylor ML, Gómez BL, Theodoro RC, Hooget S, et al. Worldwide phylogenetic distributions and population dynamics of the genus Histoplasma. PLoS Negl Trop Dis. 2016;10(6):e0004732.

12. Silveira E, Mottin IB, Ehlers A, Marques SMT. Histoplasmose felina disseminada: relato de um caso. PUBVET. 2016;10(3):207-11.

13. Figueiredo FB, Vasconcelos TCB, Reis RS, Pereira SA. Infecção natural por Histoplasma capsulatum em cão residente em bairro da Zona Sul do município do Rio de Janeiro, RJ relato de caso. Rev Bras Med Vet. 2016;38(2):125-7.

14. Crivellenti LZ, Borin-Crivellenti S. Doenças infecciosas. In: Borin-Crivellenti S, Crivellenti LZ. Casos de rotina em medicina veterinária de pequenos animais. 2a ed. São Paulo: MedVet; 2015. p. 163-4.

15. Tyre E, Eisenbart D, Foley P, Burton S. Histoplasmosis in a dog from New Brunswick. Can Vet J. 2007;48(7):734-7.

16. Silva AV, Bosco SMG. Histoplasmose. In: Megid J, Ribeiro MG, Paes AC. Doenças infecciosas em animais de produção e de companhia. Rio de Janeiro: Rocca; 2016. p. 929-35.

17. Azar MM, Hage CA. Laboratory diagnostics for histoplasmosis. J Clin Microbiol. 2017;55(6):1612-20.

18. Jardim MPB, Silva ML, Jesus AC, Cid GC, Damico CB, Santos CRGR, et al. Histoplasmose pulmonar grave em um gato doméstico: tratamento com Anfotericina B e Itraconazol. Acta Sci Vet. 2018;46:8.

19. Kauffman CA. Histoplasmosis: a clinical and laboratory update. Clin Microbiol Rev. 2007;20(1):115-32.

Recebido em: 04/11/2020 Aceito em: 03/03/2021 